\title{
Le Moyen Age de Gaston Paris, sous la direction de Michel Zink
}

\section{Maria Colombo Timelli}

\section{(2) OpenEdition}

1 Journals

\section{Édition électronique}

URL : http://journals.openedition.org/studifrancesi/32757

DOI : 10.4000/studifrancesi.32757

ISSN : 2427-5856

Éditeur

Rosenberg \& Sellier

\section{Édition imprimée}

Date de publication : 1 décembre 2005

Pagination : 608-609

ISSN : 0039-2944

\section{Référence électronique}

Maria Colombo Timelli, «Le Moyen Age de Gaston Paris, sous la direction de Michel Zink », Studi

Francesi [En ligne], 147 (XLX | III) | 2005, mis en ligne le 30 novembre 2015, consulté le 18 avril 2021.

URL : http://journals.openedition.org/studifrancesi/32757 ; DOI : https://doi.org/10.4000/

studifrancesi.32757

Ce document a été généré automatiquement le 18 avril 2021.

\section{(c)}

Studi Francesi è distribuita con Licenza Creative Commons Attribuzione - Non commerciale - Non opere derivate 4.0 Internazionale. 


\title{
Le Moyen Age de Gaston Paris, sous la direction de Michel Zink
}

\author{
Maria Colombo Timelli
}

\section{RÉFÉRENCE}

Le Moyen Age de Gaston Paris, sous la direction de MICHEL ZINK, Paris, Odile Jacob, 2004, pp. 342.

1 Ce volume réunit les actes du colloque organisé au Collège de France pour célébrer le centenaire, en 2003, de la mort de G.P., selon les mots de Michel Zink «le fondateur des études modernes de langue et de littérature médiévales en France» (p. 7). Les contributions ont été regroupées selon trois axes.

2 Le premier groupe est consacré au Portrait intellectuel.

3 Ursula BÄHLER, G.P. et la philologie romane: quelques réflexions synthétiques, pp. 13-40. Auteur d'un livre important sur G.P. (Genève, Droz, 2004), U.B. discute, dans des pages stimulantes et solidement documentées, quatre préjugés qui, à ses yeux, circulent aujourd'hui encore sur le philologue et sur sa réflexion sur le Moyen Âge français: son prétendu 'positivisme', son 'romantisme', son insensibilité à l'égard de l'esthétique des textes médiévaux, son nationalisme.

4 Michel stanesco, G.P. et la tradition poétique: une herméneutique de l'identité, pp. 41-68. Si les travaux de G.P. ne répondent plus à notre désir d'information sur la littérature du Moyen Âge, sa 'modernité' repose plutôt sur quelques intuitions qui, selon M.S., ont nourri la réflexion critique du $\mathrm{XX}^{\mathrm{e}}$ siècle, notamment la nécessité d'aborder cette littérature par une méthode scientifique, sa continuité par rapport à la littérature postérieure, la question de la poésie orale, l'empreinte nécessairement comparatiste dans les recherches médiévales.

5 Hans Ulrich GUMBRECHT, G.P. en 1871, pp. 69-80. À partir d'un rapide portrait de Paulin Paris, H.U.Gumbrecht esquisse d'abord l'ambition scientifique qui anima les recherches de G.P. sur le Moyen Age. La lecture de la leçon inaugurale au Collège de France (1780), 
sur «La Chanson de Roland et la nationalité française», permet de reconnaître la volonté de voir dans les anciens textes des documents historiques, mais surtout de rendre à nouveau présent le passé médiéval.

6 Jacqueline CERQUIGLINI-TOULET, Le dilettante et l'érudit: Jules Lemaître juge de G.P., pp. 81-88. Dans le compte rendu qu'il a donné en 1885 de La poésie du Moyen Âge de G.P. (paru la même année), J. Lemaître exprime ses reproches aux philologues (érudition, pédantisme), tout en reconnaissant à G.P. le mérite de l'amour pour la vérité et pour la patrie. Selon J. Cerquiglini-Toulet les deux savants incarnent la tension entre belleslettres et philologie, engagement conservateur et liberté de pensée.

Un deuxième volet a pour titre L'approche de la di- scipline; il s'agit en réalité de plusieurs disciplines différentes: mythologie comparée et lexicographie, littérature médiévale et histoire.

Jean-Claude CHEVALIER et Gabriel BeRgoUnIOUX, G.P. et la mythologie comparée, pp. 91-111. Après avoir tracé le cadre des études de mythologie comparée en France dans la seconde moitié du XIX siècle, J.-C. Chevalier et G. Bergounioux analysent les deux œuvres de G.P. qui portent l'empreinte de cette discipline: l'Histoire poétique de Charlemagne (1865) et l'essai sur Le Petit Poucet (1868, nouvelle édition augmentée en 1875).

9 Takeshi matsumura, G.P. et la lexicographie, pp. 113-130. Comme le rappelle T. Matsumura au début de son essai, «le vocabulaire a toujours intéressé G.P.» (p. 113): cependant, ses contributions aux études lexicographiques sont dispersées dans des notices étymologiques, des glossaires d'édition, voire dans des comptes rendus et des articles d'histoire littéraire. Les répertoires plus récents (Godefroy, ToblerLommatzsch, FEW) n'ont pas toujours tenu compte de ces remarques: l'on a donc tout intérêt de nos jours encore à relire l'ensemble des travaux de G.P., quitte à en faire une lecture critique.

10 Patrizia GASPARINI, Le rôle de la tradition dans la circulation de la littérature médiévale: G.P., Pio Rajna et Aleksandr N. Veselovskij, pp. 131-160. Dans le long compte rendu qu'il consacra aux Origini dell'epopea francese de Pio Rajna («Romania», XIII, 1884), G.P. exprime une adhésion d'ensemble aux idées du médiéviste italien, mais aussi des divergences quant à la notion de 'poème épique' et à la place à attribuer à la tradition orale dans le parcours menant aux chansons de geste. P. Gasparini analyse aussi un deuxième compte rendu de l'ouvrage de Rajna, jusqu'ici inconnu, publié dans la «Revue du Ministère de l'Instruction publique» (1885), par Aleksandr N. Veselovskij, ami de G.P. et maître reconnu des médiévistes russes.

11 Stephen Nichols, G.P. et les sens de l'histoire, pp. 161-173. Au premier plan de l'horizon intellectuel de G.P., l'histoire l'amène à considérer les œuvres poétiques médiévales comme des documents: il s'agit d'une part de découvrir l'histoire à travers la lecture des textes, de l'autre de replacer l'œuvre dans son propre contexte historique et littéraire; du coup, l'histoire littéraire s'en trouve élevée au niveau d'une véritable science, au même titre que l'histoire politique et sociale. S. Nichols offre deux cas d'espèce de cette lecture par G.P.: la Vie de Saint Louis de Joinville (dans «Romania», XXIII, 1894), et le roman de Richard Cour de Lion («Romania», XXVI, 1897).

Un dernier axe est centré sur 'Romania' et Romanistes européens.

13 Karlheinz STIERLE, G.P. et l'unité de la 'Romania', pp. 177-192. K. Stierle analyse l'article Romani, Romania, lingua romana, Romancium, véritable manifeste qui ouvre le premier 
numéro de la revue fondée par G.P. et Paul Meyer en 1872. Il en ressort une idée d'unité de la Romania fondée sur un sentiment d'appartenance à une même civilisation européenne qui exclut toute glorification d'une race, mais qui n'empêchera nullement G.P. de se consacrer à l'exploration et à l'étude du Moyen Âge de sa propre nation.

Charles RIDoux, La dimension européenne de G.P., pp. 193-209. La dimension européenne est constamment présente dans la pensée et l'activité de G.P.: son profond attachement à sa patrie et à l'héritage français fut toujours en équilibre avec le sens d'appartenance à une communauté scientifique supra-nationale. C. Ridoux retrace les liens personnels que G.P. tissa pendant des décennies avec des romanistes de l'Europe entière (Allemagne, Autriche, Belgique, Pays-Bas, pays scandinaves, Espagne, Italie) et souligne le rayonnement exceptionnel dont il jouit lui-même et qui fit de lui une figure emblématique de l'Europe savante et cultivée de son temps.

Anne-Marguerite FRYBA-REBER, Les romanistes suisses et G.P., pp. 211-242. Il s'agit d'une esquisse des rapports qui s'établirent au cours des années entre G.P. et les jeunes savants suisses montés à Paris pour suivre les cours de l'EPHE. A.-M. Fryba-Reber reconstruit d'abord le contexte universitaire suisse (avec l'institutionnalisation de la philologie romane à Zurich, Bâle, Berne, Lausanne, Fribourg, Genève, Neuchâtel), pour étudier ensuite le rayonnement des romanistes suisses (Gilliéron, Meyer-Lübke) à l'étranger, et conclut sur les rapports entre G.P. et Ferdinand de Saussure.

16 Guido LUcchinI, L'influence de G.P. sur les philologues de son époque en Italie, pp. 243-288. Les témoignages sont nombreux de l'influence de G.P. sur les philologues romans italiens. G. Lucchini rappelle surtout Alessandro D'Ancona, divulgateur de ses études en Italie, longtemps en correspondance avec G. Paris et P. Meyer, et Pio Rajna, dont on connaît les divergences avec G.P. à propos de la diffusion de l'épopée française dans la Péninsule et sur le Saint Alexis. En appendice sont publiées deux lettres inédites de D. Comparetti et G.P. (mars / juillet 1867).

17 Alain CORBELLARI, L'héritage spirituel de G.P. à travers la correspondance inédite de Joseph Bédier, pp. 289-298. C'est à Joseph Bédier que revient le rôle de gardien incontesté de la mémoire de G.P. Bédier en fut l'héritier à plusieurs égards: secrétaire de l'Association des Amis de G.P. dès sa fondation, héritier de sa chaire au Collège de France, éditeur de l'article posthume sur le «Conte de la Gageure», auteur, avec la précieuse collaboration de Mario Roques, de la Bibliographie de G.P.

18 Une trentaine de pages en fin du volume (pp. 319-340) contiennent les résultats d'une table ronde à laquelle ont participé, outre les auteurs des communications, Michel Zink, Claudio Galderisi, David Hult. 